\title{
First Occurrence of the Round Goby, Neogobius melanostomus, in the St. Lawrence River at Cornwall, Ontario
}

\author{
M. BRIAN C. HICKEY ${ }^{1}$ and ADRIENNE R. FOWLIE ${ }^{2}$ \\ ${ }^{1}$ St. Lawrence River Institute of Environmental Sciences, Windmill Point, 2 Belmont Street, Cornwall, Ontario K6H 4Z1 \\ Canada; e-mail: bhickey@ riverinstitute.ca \\ ${ }^{2}$ Queen's University, Kingston, Ontario K7L 3N6 Canada; e-mail: fowliea@ biology.queensu.ca
}

Hickey, M. Brian C., and Adrienne R. Fowlie. 2005. First occurrence of the Round Goby, Neogobius melanostomus, in the St. Lawrence River at Cornwall, Ontario. Canadian Field-Naturalist 119(4): 582-583.

We document the first reported occurrence of the Round Goby, Neogobius melanostomus, a small benthic fish native to the Black and Caspian seas, in the St. Lawrence River near Cornwall. On 7 September 2004, we observed approximately 20 Round Gobies while SCUBA diving at a depth of $7 \mathrm{~m}$, downstream of the Saunders Generating Station at Cornwall, Ontario. Round Gobies appear to have arrived recently in this reach of the river and have not previously been detected despite extensive fish surveys conducted in the area.

Key Words: Round Goby, Neogobius melanostomus, exotic species, St. Lawrence River, Cornwall, Ontario.

The Round Goby, Neogobius melanostomus, is a small benthic fish native to the Black and Caspian seas (Charlebois et al. 2001). It was introduced to the Great Lakes from Eurasia in ballast water of transoceanic ships (Charlebois et al. 2001). The first reported sighting of Round Goby was in Lake St. Clair in 1990, and within five years, the species was reported in all five Great Lakes (Charlebois et al. 2001). Reasons for this rapid expansion include its high fecundity, wide tolerance of abiotic factors, and broad diet (French and Jude 2001; Corkum et al. 2004).

The Round Goby's expansion in to the Great Lakes has been rapid but movement into the St. Lawrence River has been much slower; perhaps an indication that habitat or hydraulic conditions are sub-optimal in the St. Lawrence. Gobies have been recorded upstream of the Moses-Saunders Dam as close as Prescott, Ontario (approximately $100 \mathrm{~km}$ upstream) and in the lower St. Lawrence near Quebec City. The geographic distribution of the Round Goby suggests that there have been at least two separate introductions but we are not aware of any studies that confirm this view. To our knowledge, they have not been previously recorded in the Cornwall area.

Their absence from the Cornwall area is probably a real phenomenon rather than the result of lack of detection. The St. Lawrence River between the MosesSaunders Dam and the Beauharnois Dam in Quebec has been designated an Area of Concern (AOC) by the International Joint Commission. Consequently, the Cornwall area has been the focus of several ongoing biological investigations which have included regular surveys of the littoral zone fish community (Dreier et al. 1997; M. B. C. Hickey unpublished data). These surveys have included electrofishing, minnow trapping, and gill netting as well as snorkel and dive transects along an 8-km stretch of the St. Lawrence between the Moses-Saunders Dam and Windmill Point.
On 7 September 2004, we observed approximately 20 Round Gobies while SCUBA diving at a depth of $7 \mathrm{~m}$, downstream of the Saunders Generating Station at Cornwall, Ontario ( $\left.45^{\circ} 00^{\prime} 31^{\prime \prime} \mathrm{N}, 74^{\circ} 46^{\prime} 09^{\prime \prime}\right)$. The Round Goby's distinctive body shape and conspicuous dorsal fin spot (Figure 1) make it easy to distinguish from other small benthic fish reported from the St. Lawrence River (e.g., darters, Etheostoma sp. and sculpins, Cottus sp.). On two dives, less than $3 \mathrm{~km}$ downstream of the site where we observed round gobies on 7 September 2004, we did not notice gobies, suggesting that the gobies we observed represent the leading edge of their expansion in the St. Lawrence River as they move downstream from the upper St. Lawrence River.

The invasion of the Round Goby poses potential threats to native species such as the sculpins and darters that occupy similar habitat but are unable to compete for resources with the more aggressive gobies (Janssen and Jude 2001). The Round Goby's use of zebra mussels as a major prey may dramatically alter the patterns of contaminant uptake in the St. Lawrence River food web. The potential role of sediment contamination in the Cornwall "Area of Concern" (Dreier et al. 1997) is the subject of several ongoing investigations (M. B. C. Hickey and A. Fowlie, unpublished data). The introduction of Round Goby and subsequent lengthening of the food chain has been associated with increased levels of PCBs in fish of higher trophic levels in western Lake Erie (Morrison et al. 2000). The recent expansion of Round Goby in the St. Lawrence River AOC at Cornwall could produce similar effects in mercury biomagnification which has been shown to increase with food chain length (Cabana et al. 1994). Given the potential ecological and economic impacts of Round Goby invasion, the Cornwall area may provide a natural laboratory in which to study the impacts of the Round Goby and ultimately devise mitigation or control measures. 


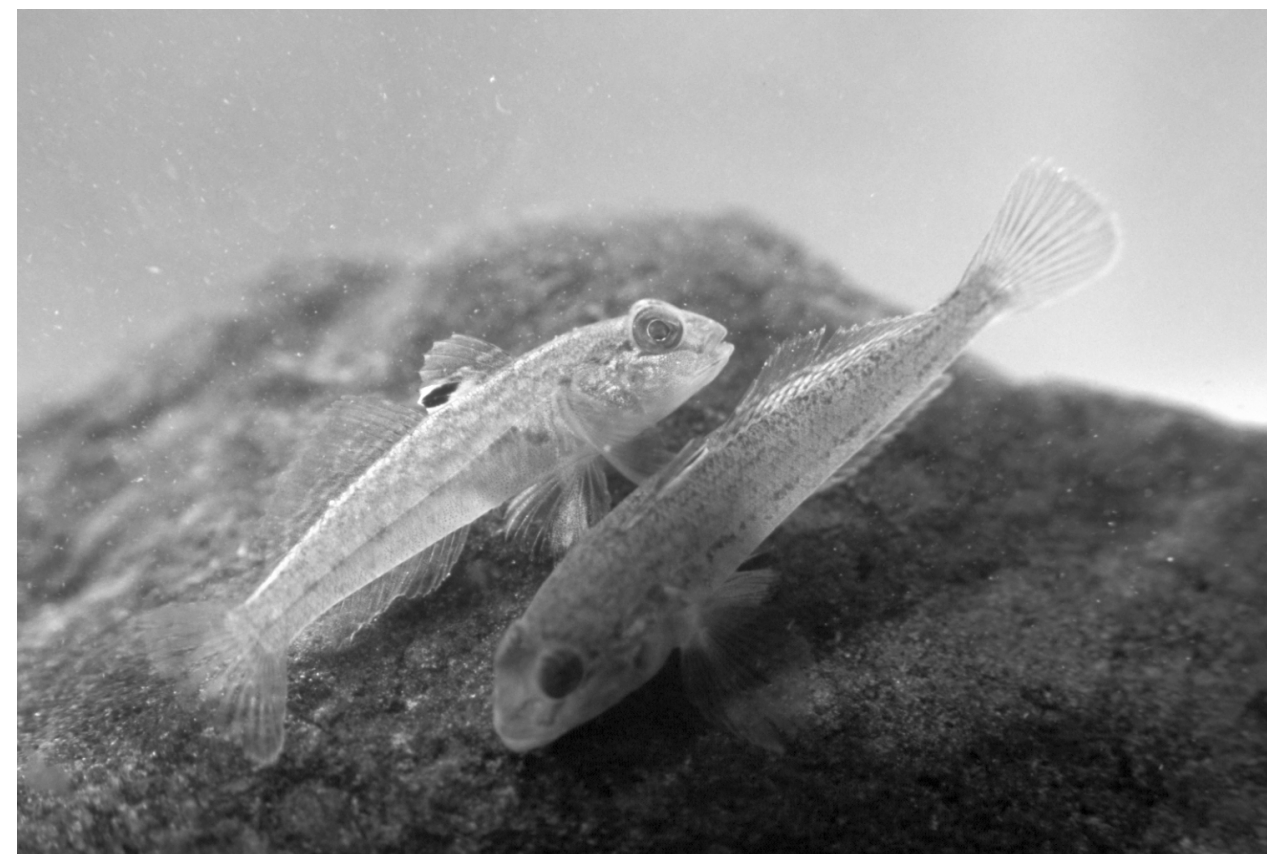

FIGURE 1. Round Gobies, Neogobius melanostomus, captured in the St. Lawrence River, immediately downstream of the Saunders Generation Station at Cornwall, Ontario. Photo by M. B. C. Hickey and A. R. Fowlie.

\section{Acknowledgments}

We thank Jason Szwec, Rob Marion and Jessica Roy for assisting us in the field and Jason Szwec and Rob Gratton for reviewing an earlier version of the manuscript. Sean Hickey and Lisa Hickey assisted with the capture of the Round Gobies photographed for Figure 1.

\section{Literature Cited}

Cabana, G., A. Tremblay, J. Kalff, and J. B. Rasmussen. 1994. Pelagic food chain structure in Ontario lakes: A determinant of mercury levels in Lake Trout (Salvelinus namaycush). Canadian Journal of Fisheries and Aquatic Sciences 51: 381-389.

Charlebois, P. M., L. D. Corkum, D. J. Jude, and C. Knight. 2001. The round goby Neogobius melanostomus invasion: current research and future needs. Journal of Great Lakes Research 27: 263-266.

Corkum, D. L., M. R. Sapota, and K. E. Skora. 2004. The round goby, Neogobius melanostomus, a fish invader on both sides of the Atlantic Ocean. Biological Invasions 6: 173-181.
Dreier, S. I., J. Anderson, J. Biberhofer, M. Eckersley, R. Helliar, M. B. C. Hickey, L. Richman, F. Stride, and The St. Lawrence Remedial Action Plan Public Advisory Committee. 1997. Great Lakes Great River: Remedial Action Plans for the St. Lawrence River (Cornwall) Area of Concern. 203 pages.

French, J. R. P., III, and D. J. Jude. 2001. Diets and diet overlap of nonindigenous gobies and small benthic native fishes co-inhabiting the St. Clair River, Michigan. Journal of Great Lakes Research 27: 300-311.

Janssen, J. and D. J. Jude. 2001. Recruitment failure of mottled sculpin (Cottus bairdi) in Calumet Harbor, southern Lake Michigan, induced by the newly introduced round goby Neogobius melanostomus. Journal of Great Lakes Research 27: 319-328.

Morrison, H. A., D. M. Hittle, and G. D. Haffner. 2000. The relative importance of species invasions and sediment disturbance in regulating chemical dynamics in western Lake Erie. Ecological Modeling 125: 279-294.

Received 7 February 2005

Accepted 12 December 2005 